FREITAS, A.I.A. Pododermatite no gado de leite - Revisão de literatura. PUBVET, Londrina, V. 5, N. 30, Ed. 177, Art. 1193, 2011.

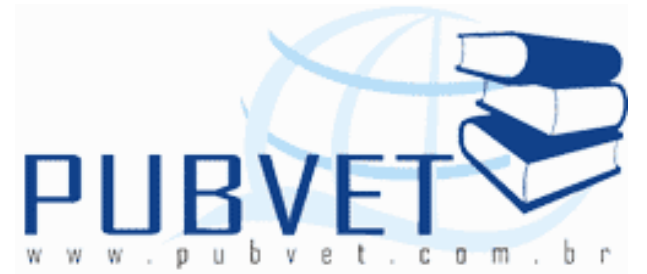

PUBVET, Publicações em Medicina Veterinária e Zootecnia.

\title{
Pododermatite no gado de leite - Revisão de literatura
}

\section{Andressa Izabel Assis Freitas}

Médica Veterinária

\section{Resumo}

A procura de métodos para reduzir os custos de produção de leite tem levado os criadores a adotarem medidas de alteração do manejo dos rebanhos, passando, em muitos casos, dos sistemas extensivos e semi-extensivo para o sistema de confinamento. No entanto, devido a este sistema, alguns problemas relativos à saúde dos cascos e aprumo poderão surgir, causando perdas econômicas referentes à redução na vida útil dos animais, diminuição da produção leiteira, perda de performace reprodutiva ou, em casos mais graves, o sacrifício precoce dos animais. Dentre as afecções podais, a pododermatite é uma das mais freqüentes nos rebanhos de gado leiteiro, causada pela penetração de bactérias do solo - Dichelobacter nodosus e Fusobacterium necrophorus em algum tipo de lesão inicial ou micro lesão nas partes sensíveis dos pés dos bovinos.

Palavras-chaves: Afecções podais, Gado leiteiro, Pododermatite.

\section{Foot pad dermatitis in Milk Cattle - Literature Review}

\begin{abstract}
The search for methods to reduce the costs of milk production has led farmers to adopt alteration measures of herd management, from extensive and semi-
\end{abstract}


FREITAS, A.I.A. Pododermatite no gado de leite - Revisão de literatura. PUBVET, Londrina, V. 5, N. 30, Ed. 177, Art. 1193, 2011.

extensive to confinement system. However, due to this system, some issues related to the health of the hoofs and aplombs - can arise, causing economical losses concerning the reduction of the animal's useful life, decrease in milk production, loss of reproductive performance, or, in most serious cases, the animal's early sacrifice. Among the podal affections, the foot pad dermatitis is one of the most frequent in the herds of dairy cattle, caused by the penetration of soil bacteria Dichelobacter nodosus and Fusobacterium necrophorus into some kind of initial lesion or micro lesion in sensitive parts of the bovine's feet.

Key words: the podal affections, milk cattle, Foot pad dermatitis.

\section{Introdução}

As afecções podais são consideradas como um dos maiores problemas de saúde em gado de leite(FAYE \& LESCOURRET,1989). Nos bovinos, das enfermidades causadoras de claudicação, doença dos dígitos como dermatite interdigital, erosão ungular, dermatite verrucosa, dermatite digital, flegmão interdigital entre outras a pododermatite é a mais freqüente na exploração do gado leiteiro.

A pododermatite é uma doença infecciosa, caracterizada por inflamação da região interdigital, na junção da pele com o casco,além de claudicação grave e lesões da aspécto necrótico purulento. Também chamada de FOOT HOT, ou seja, "frieira é causada por bactérias do solo como Fusobacterium necrophorus e Dichelobacter nodosus.

A importância da pododermatite deve-se aos graves prejuízos na produtividade e à economia da propriedade, além da redução da vida útil dos animais, diminuição da produção leiteira, diminuição da fertilidade e custo do tratamento.

O objetivo desta revisão é descrever sobre as afecções podais do gado de leite, tema de grande interesse e importância para produtores, veterinários 
FREITAS, A.I.A. Pododermatite no gado de leite - Revisão de literatura. PUBVET, Londrina, V. 5, N. 30, Ed. 177, Art. 1193, 2011.

e zootecnistas, que se deparam com uma certa freqüência com essa enfermidade.

\section{Etiologia}

A etiologia e descrição das diversas formas das afecções do casco foram estudadas por vários autores (SARAIVA,1984; PESCE 3L 3L., 1992; EDMONSON, 1994; BLOWEY \& DONE, 1995), sendo as bactérias anaeróbias Dichelobacter nodosus e Fusobacterium necrophorum os principais agentes infecciosos envolvidos (PESCE 3L L., 1992). DURAN 3L 3L.(1990) isolou inúmeras bactérias anaeróbicas e cocluíram que a pododermatite também conhecida como podridão dos cascos e FOOT HOT ("frieira") é, provavelmente, um processo multifocal, resultante da invasão de uma lesão prévia do casco por bactérias presentes no solo. A infestação por Chorioptes bovis é sugerida como uma provável causa desencadeante de úlceras podais (MONLUX, 1961), mas freqüentemente não existe este ácaro em fazendas onde são comuns tais moléstias.

\section{Pododermatite}

A procura de métodos para reduzir os custos de produção de leite tem levado os criadores a adotarem medidas de alteração de manejo dos rebanhos, passando em muitos casos, dos sistemas extensivos e semi-extensivos para o sistema de confinamento. No entanto, devido a estes sistemas de confinamento adotado para tais animais vem causando problemas nos cascos e aprumos, podendo trazer como conseqüência mais grave a redução da vida produtiva do animal.

Nos bovinos, das doenças dos dígitos como dermatite interdigital, erosão ungular, dermatite verrucosa, dermatite digital, flegmão interdigital, hiperpalsia interdigital entre outras, a pododermatite séptica é a mais comum (NOCEK,1993). 
FREITAS, A.I.A. Pododermatite no gado de leite - Revisão de literatura. PUBVET, Londrina, V. 5, N. 30, Ed. 177, Art. 1193, 2011.

As afecções podais são consideradas como um dos maiores problemas de saúde em gado de leite (FAYE \& LESCOURRET,1989), sendo superadas apenas pelas alterações reprodutivas e pela mastite como causa de descarte nos rebanhos leiteiros (BORGES \& GARCIA, 1997).

A incidência da enfermidade é alta durante o tempo úmido ou quando há umidade no solo. Os solos pedregosos, os caminhos cheios de cascalhos pontiagudos e o pastoreio em restolho grosso também predispõe à doença. A pododermatite é observada durante todo o ano e a prevalência é maior nas estações úmidas (SMITH, 1994). Entretanto, esta enfermidade também pode ocorrer com certa freqüência nas estações secas, quando o terreno está firme (FRASER, 1991). Outros autores afirmam que a doença é mais comum durante o inverno, período em que os animais, por estarem estabulados, passam horas sobre suas excretas (GREENOUGH, 1997) e urina. Embora a doença ocorra mais comumente quando os bovinos são mantidos em condições insalubres, foi encontrado casos em rebanhos bem manejados. Outras causas para tal moléstia podem ser: o excesso de alimentação à base de carboidratos, falta de higiene, aftosa, ou mesmo em caso de febre alta por infecções.

A ocorrência em bovinos leiteiros depende do sistema de manejo, do ambiente e da raça. Os bovinos de todas as idades, inclusive ao bezerros jovens, podem ser cometidos, mas a doença é mais comum em adultos. Uma observação de campo è que o Bos indicus (tipo Zebu e Brahma) é muito mais resistente às úlceras podais infecciosas do que as raças de Bos taurus (FRISCH, 1996). As raças taurinas, especialmente a Holandesa, são bem mais sensíveis que as zebuínas (BORGES \& GARCIA,1997). Para RUSSELL et aL., as raças mais pesadas, como a Holandesa, são mais susceptíveis que raças leves como Ayrshire, Guernsey e Jersey. Os animais com problemas podas andam menos, ficam para trás do rebanho, alimentam-se menos, mantém-se sempre perto de aguadas, não exteriorizam os sinais de cio e permanecem grande parte do tempo em decúbito, consequentemente, observa-se uma alteração na performance reprodutiva, principalmente com relação a ocorrência de anestro (BERTERO,1992). Dessa forma, perdas econômicas referente a vida útil dos 
FREITAS, A.I.A. Pododermatite no gado de leite - Revisão de literatura. PUBVET, Londrina, V. 5, N. 30, Ed. 177, Art. 1193, 2011.

animais, diminuição da produção de leite, diminuição da fertilidade e custo de tratamento são considerados graves problemas(GREENOUGH et al.,1983,e WEAVER,1988). Em outras palavras, a enfermidade não é fatal, mas pode ser necessário o abate de alguns animais devido ao comprometimento articular.

A classificação das enfermidades dos dígitos dos bovinos pode ser realizada de maneiras distintas e a terminologia varia de país para país e entre os autores (DEMIRKAN et al., 2000). A nomenclatura para caracterizar as lesões podais em bovinos não está bem padronizada, o que resulta em confusões por parte dos técnicos.

\section{Aspécto clínico}

Esta enfermidade em bovinos caracteríza-se por inflamação dos tecidos sensitivos das patas e claudicação grave. Quanto ao aspécto clínico, GREENOUGH et al.(1987), propuseram uma terminologia para classificação das afecções dos pés de bovinos, que consiste em um método prático baseado na localização anatômica da lesão. Existem três estágios de evolução da doença sendo o agudo nos primeiros dez dias, o subagudo de dez a quarenta e cinco dias e o crônico acima de quarenta e cinco dias (NOCEK,1993; GREENNOUGH, 1962).

A fase inicial da doença caracteriza-se por tumefação na pele do espaço interdigital, acompanhada de claudicação, aumento de volume da extremidade do membro e, em alguns casos, fistulação com exsudação de líquido sanguinolento de odor desagradável, sem lesões macroscopicamente visíveis no estojo córneo, espaço interdigital, perioplo, sola e talão (SILVA et al.,1998), é observado hiperemia da região ungular, perceptível sensibilidade ao toque e presença de pontos amarelos na pele do espaço interdigital. A fase aguda é uma infecção que apresenta edema duro devido à inflamação do tecido subcutâneo na parte posterior e/ou espaço interdigital (GREENOUGH,1997). Possui odor característico e pode se estender dorsalmente ao espaço interdigital e articulação podal, produzindo artrite purulenta. Contudo, a 
FREITAS, A.I.A. Pododermatite no gado de leite - Revisão de literatura. PUBVET, Londrina, V. 5, N. 30, Ed. 177, Art. 1193, 2011.

evolução clínica agrava-se, com o local do edema mais sensível, evoluindo para fistulação no espaço interdigital, com presença de secreção sanguinolenta em alguns animais e massa caseosa com odor pútrido fluindo pela lesão em todos os bovinos enfermos (BLOWEY,1992).

\section{Controle e prevenção}

O gado de leite estabulado em sistema de confinamento requer mais atenção quanto aos cuidados com o casco e subseqüentes cortes ou aparo de cascos ("toilette"). A unha é uma estrutura sólida compacta, elástica e sensível. Ela aumenta de volume e amolece com a umidade, e se contrai e quebra em ambiente quente e seco (D'AUTHEVILLE, 1988).

Quando não se faz qualquer tipo de tratamento ou este é ineficaz, podem ocorrer lesões irreversíveis nos dígitos e, nas infecções crônicas, os cascos tornam-se longos e disformes (GREENOUGH, 1997).

Como prevenção, além de vacinações, as instalações da propriedade devem ser piso e área adequados para permitir que os animais se exercitem sobre superfície firme, livre do material abrasivo e cortante. Aterro de trechos barrentos e pedregosos em currais e caminhos reduz a incidência da enfermidade. Desta forma será mantida uma boa circulação sanguínea e um desgaste normal dos cascos. A área de alimentação deve situar-se afastada da área de dormir, com dimensionamento adequado ao número de animais existentes no rebanho (BLOWEY,1992). O uso de pedilúvio com solução de sulfato de cobre e formaldeído de 5 a $10 \%$, duas vezes ao dia (na entrada e saída da sala de ordenha) diminui consideravelmente o aparecimento de pododermatite (RADOSTITS et al.,1994). Freqüentemente se usa uma mistura de sulfato de cobre a $10 \%$ em cal extinta dessa mesma forma. 
FREITAS, A.I.A. Pododermatite no gado de leite - Revisão de literatura. PUBVET, Londrina, V. 5, N. 30, Ed. 177, Art. 1193, 2011.

\section{Considerações finais}

A ocorrência das afecções podais são muito comuns no rebanho de gado leiteiro. Suas causas estão relacionadas a diversos fatores, como: o caráter da raça, já que algumas são mais resistentes que outras; o manejo, devido ás condições de higiene dos estábulos; a nutrição dos animais, pois indivíduos que são alimentados com excesso de concentrado possuem cascos menos resistentes além dos efeitos ambientais, como clima, temperatura e solo. Para tal enfermidade, a prevenção é a melhor escolha em relação a custo e benefício, e o mesmo pode ser feito com a instalação do pedilúvio, além do manejo e nutrição adequado para os animais.

\section{Referências}

BERTERO, J. Exloracion clínica del pie del bovino. In:PESCE, L. (ED.) Enfermidades podais de los ruminantes. Montevideo:Hemisfério Sur, p.3-16., 1992.

BORGES, J.R.J.; GARCIA, M. Guia Bayer de podologia bovina. Rio de Janeiro: Sony Music, 1 CD ROOM. 1997.

BLOWEY, R. Diseases of the bovine digit. Parte 1- description of common lesions. In Pract, p. 85-90, 1992.

BLOWEY, R.W., DONE, S.H. Failure to demonstrate histological changes of digital or interdigital dermatitis in biopsies of slurry heel. Vet. Rec., v.7, p.379-380, 1995.

D'AUTHEVILLE, P.; FROMOUD, P. Manual de ferradura eqüina. Organização Andrei, 2ed., p.45-61., 1998.

DEMIRKAN, I.; MURRAY, R. D.; CARTER, S. D. Skin diseases of the bovine digit associated with lameness. Veterinary Bulletin, v. 70, n. 2, p. 149-171,2000.

DURAN, S.P., MANZANO, J.V., VALERA, R.C. et al. Obligately anaerobic bacterial species isolated from foot-rot lesions in goats. Br. Vet. J., v.146, p.551-558, 1990.

EDMONDSON, In: SMITH, B.P. Tratado de medicina interna de grandes animais. São Paulo: Manole, v.2, 1738p., 1994.

FAYER,B.; LESCOURRET,F. Environmental factors associated with lameness in dairy cattle. Prev. Vet. Med. V.7, p.267-287, 1989.

FRASER, C. M. Manual Merck de veterinária. 6. ed., São Paulo: Roca, 1803 p., 1991.

FRISCH, J.E. Aust. Vet. J., 52-228.,1996. 
GREENOUGH, P. R. Cascos irregulares são sinais de problemas. Balde Branco, n. 388, p. 9 $-13,1997$.

GREENOUGH, P. R. et al. Les boiteries des bovines. 3.ed.Paris:Du Point. Veterinaire, 478p. 1983.

GREENOUGH, P. R. Observations on some of the diseases of the bovine foot, part II. The Veterinary Record, v. 74, n. 2, p. 53-63, 1962.

MONLUX, W.Set al. J. Am. Vet. Med. Ass., 138,379., 1961.

NOCEK,J.E. Hoof care for dairy cattle. Fort Atkinson: W.D.Hoards \& Sous Co.,p.32. 1993.

PESCE, L., BERMUDEZ, J., BONINO, J. et al. Enfermidades podais de los ruminantes. Montevidéo: Hemisfério Sur, 168 p., 1992.

RADOSTTIS. O. M. et al. Veterinary medicine. 8.ed.London: W.B. Saunders, 1763p,1994.

RUSSEL, J , B. Quimica Geral. et. Al. 2. ed - MOKRON BOOKS. São Paulo. 1994.

SARAIVA, D. et al. Bacteriologia especial de interesse em saúde animal e saúde pública. Porto Alegre: Sulina. 492p., 1984.

SMITH, B. P. Tratado de medicina interna de grandes animais. São Paulo: Manole, 1738 p., 1994.

WEAVER, A. D. Chirurgie and lahmheit beim rind. Stutgart: gustav Fischer Verlag, 245p., 1988. 